\title{
Spatial and temporal variation in the abundance of Culicoides biting midges (Diptera: Ceratopogonidae) in nine European countries
}

Ana Carolina Cuéllar ${ }^{1 *}$, Lene Jung Kjær ${ }^{1}$, Carsten Kirkeby ${ }^{1}$, Henrik Skovgard², Søren Achim Nielsen³, Anders Stockmarr ${ }^{4}$, Gunnar Andersson ${ }^{5}$, Anders Lindstrom ${ }^{5}$, Jan Chirico ${ }^{5}$, Renke Lühken ${ }^{6}$, Sonja Steinke ${ }^{7}$, Ellen Kiel' Jörn Gethmann ${ }^{8}$, Franz J. Conraths ${ }^{8}$, Magdalena Larska ${ }^{9}$, Inger Hamnes ${ }^{10}$, Ståle Sviland ${ }^{10}$, Petter Hopp ${ }^{10}$, Katharina Brugger ${ }^{11}$, Franz Rubel ${ }^{11}$, Thomas Balenghien ${ }^{12}$, Claire Garros ${ }^{12}$, Ignace Rakotoarivony ${ }^{12}$, Xavier Allène ${ }^{12}$, Jonathan Lhoir ${ }^{12}$, David Chavernac ${ }^{12}$, Jean-Claude Delécolle ${ }^{13}$, Bruno Mathieu $^{13}$, Delphine Delécolle ${ }^{13}$, Marie-Laure Setier-Rio ${ }^{14}$, Roger Venail ${ }^{14,18}$, Bethsabée Scheid ${ }^{14}$, Miguel Ángel Miranda Chueca ${ }^{15}$, Carlos Barceló ${ }^{15}$, Javier Lucientes ${ }^{16}$, Rosa Estrada ${ }^{16}$, Alexander Mathis ${ }^{17}$, Wesley Tack $^{18}$ and Rene Bødker ${ }^{1}$

\begin{abstract}
Background: Biting midges of the genus Culicoides (Diptera: Ceratopogonidae) are vectors of bluetongue virus (BTV), African horse sickness virus and Schmallenberg virus (SBV). Outbreaks of both BTV and SBV have affected large parts of Europe. The spread of these diseases depends largely on vector distribution and abundance. The aim of this analysis was to identify and quantify major spatial patterns and temporal trends in the distribution and seasonal variation of observed Culicoides abundance in nine countries in Europe.

Methods: We gathered existing Culicoides data from Spain, France, Germany, Switzerland, Austria, Denmark, Sweden, Norway and Poland. In total, 31,429 Culicoides trap collections were available from 904 ruminant farms across these countries between 2007 and 2013.

Results: The Obsoletus ensemble was distributed widely in Europe and accounted for 83\% of all 8,842,998 Culicoides specimens in the dataset, with the highest mean monthly abundance recorded in France, Germany and southern Norway. The Pulicaris ensemble accounted for only $12 \%$ of the specimens and had a relatively southerly and easterly spatial distribution compared to the Obsoletus ensemble. Culicoides imicola Kieffer was only found in Spain and the southernmost part of France. There was a clear spatial trend in the accumulated annual abundance from southern to northern Europe, with the Obsoletus ensemble steadily increasing from 4000 per year in southern Europe to 500,000 in Scandinavia. The Pulicaris ensemble showed a very different pattern, with an increase in the accumulated annual abundance from 1600 in Spain, peaking at 41,000 in northern Germany and then decreasing again toward northern latitudes. For the two species ensembles and C. imicola, the season began between January and April, with later start dates and increasingly shorter vector seasons at more northerly latitudes.

(Continued on next page)
\end{abstract}

\footnotetext{
* Correspondence: anacu@vet.dtu.dk

'Division for Diagnostics and Scientific Advice, National Veterinary Institute,

Technical University of Denmark (DTU), Copenhagen, Denmark

Full list of author information is available at the end of the article
} 
(Continued from previous page)

Conclusion: We present the first maps of seasonal Culicoides abundance in large parts of Europe covering a gradient from southern Spain to northern Scandinavia. The identified temporal trends and spatial patterns are useful for planning the allocation of resources for international prevention and surveillance programmes in the European Union.

Keywords: Culicoides abundance, Seasonal abundance, Spatial pattern, Temporal trend, Vector season, Culicoides distribution, Europe, Vector-borne disease

\section{Background}

Biting midges of the genus Culicoides (Diptera: Ceratopogonidae) are important vectors of viruses among livestock, for example bluetongue virus (BTV), African horse sickness virus (AHSV) and Schmallenberg virus (SBV). The incursion of these viruses in Europe in recent decades has caused substantial economic losses to farmers in the European Union [1-8].

At least 83 species of Culicoides are found in Europe (83 species reported in France [9]) but only some of these are suspected to transmit viruses: the afrotropical vector $C$. imicola was previously considered to be the main vector of BTV in southern European countries [10], though BTV virus was also isolated from wild specimens of Culicoides obsoletus (Meigen)/Culicoides scoticus Downes \& Kettle and specimens of the Pulicaris ensemble [11-14]. During an unprecedented outbreak of BTV serotype 8 in northern Europe in 2006, it became evident that autochthonous Culicoides species of the subgenus Avaritia, specifically C. obsoletus/C. scoticus and possibly Culicoides dewulfi Goetghebuer, were transmitting the virus [15-19].

In 2000, the European Commission established a series of regulations for BTV control, including monitoring and surveillance in the affected countries. According to Commission Regulation (EC) No. 1266/2007, it is mandatory for member states to carry out bluetongue surveillance programmes that include vector monitoring [20]. As a result of the BTV outbreak in 2006, the northern European countries also started carrying out entomological surveillance of Culicoides vectors. Collections by light traps at ruminant farms have been a key component of these programmes in both southern and northern Europe.

Several European countries have gathered and analysed entomological data at a national level to determine the presence and abundance of different species of Culicoides [21-25]. In addition, vector activity during the winter has been assessed in an attempt to determine the existence of a "vector-free period" [26, 27]. Determining a vector-free period might be useful for national veterinary authorities to authorize movements of test-negative ruminants. The number of national studies from
European countries has increased during the last decade, but the need to quantify Culicoides vector dynamics at a continental level remains, as European legislation for vector-borne diseases is founded on joint decisions among the member states.

The aim of the present study was to generate a joint entomological database for large parts of Europe comprising different climatic zones, using surveillance and research data collected during the period 2007-2013. Nine European countries (Spain, France, Germany, Austria, Switzerland, Denmark, Sweden, Norway and Poland) agreed to share data and quantify key temporal and largescale geographical trends in the abundance of two main Culicoides species ensembles (Obsoletus ensemble and Pulicaris ensemble) and C. imicola.

\section{Methods \\ Culicoides database}

We gathered available Culicoides data from Spain [28], France [9, 23], Germany [24], Switzerland [29, 30], Austria [31], Denmark, Sweden [32, 33], Norway and Poland [34]. The data originated from national surveillance systems and research projects carried out during one or more years during a 7-year period (2007-2013) by national authorities and research groups. Culicoides biting midges were sampled from a total of 904 livestock farms (Fig. 1), with 31,429 trap collections comprising $8,842,998$ specimens. For entomological sampling details from the different countries see [9, 23, 24, 28-34].

Black light suction traps were placed outside stables or near animal resting sites and the coordinates of each farm were recorded. Onderstepoort traps (Onderstepoort Veterinary Institute, Pretoria, Republic of South Africa) were used to catch Culicoides from dusk until dawn in all countries [23, 29, 31, 32, 34] except Germany, where Biogents Sentinel (BG-Sentinel) traps (BioGents, Regensburg, Germany) fitted with a black light lamp were used [24], and Spain, where mini CDC model 1212 (John W. Hock, Gainesville, FL, USA) traps were used [35]. Onderstepoort traps have been reported to catch more Culicoides than the other two types of traps [36, 37]. Therefore, data obtained by the BGSentinel and mini CDC traps were converted to the 


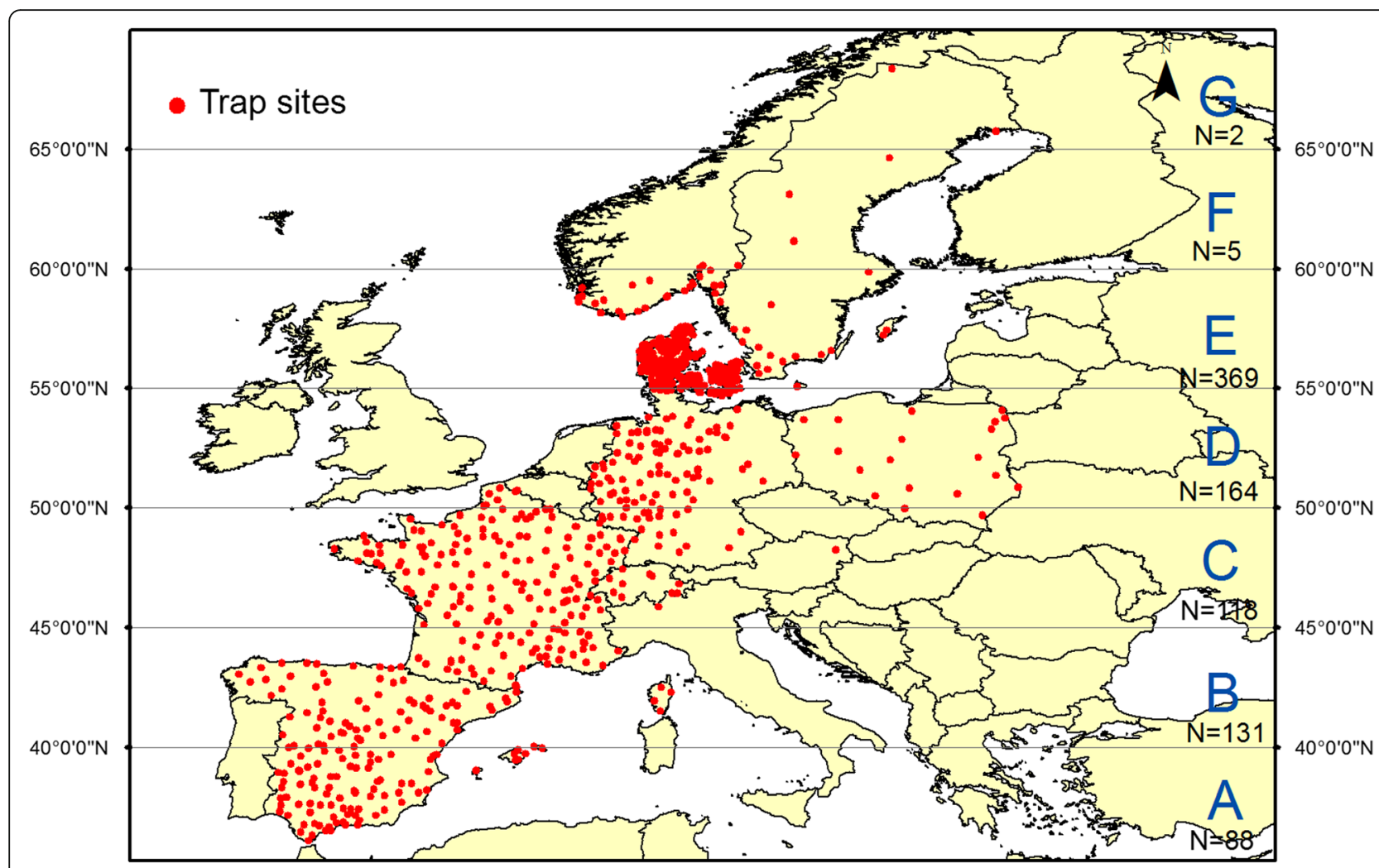

Fig. 1 Available data from sampled farms in Europe during entomological surveys from 2007 to 2013. Latitudinal ranges were defined for every 5 degrees of latitude. From south to north, latitudinal ranges were named A, B, C, D, E, F and G

number of specimens estimated to have been collected if Onderstepoort traps had been used. For BG-sentinel traps, Venter et al. [36] calculated a conversion factor of 3.1, while Probst et al. [37] calculated a conversion factor of 3.83. We used the mean of these values (3.48) as the conversion factor in this study. Three trap efficiencies $(0.404,0.288$ and 0.505$)$ were previously reported for the CDC mini trap [36]. We used the average of these values (0.399) and used the reciprocal conversion factor of 2.51 for all vector species. A single trap per farm was used in all the countries with the exception of Germany. During the 2012-2013 campaign Germany operated 3 traps per farm, so in order to have only one observation per farm we took the median amount of Culicoides caught among the 3 traps.

Some Culicoides species are difficult to identify based on morphology, e.g. C. obsoletus/C. scoticus [13, 18, 38-41]. In the data available for this analysis, specimens were identified to species level in some countries, while other countries only identified them to group level. To create a uniform database, we aggregated the species into ensembles. We use the term "ensemble" to refer to a group of sympatric species for which morphological identification is sometimes not possible or difficult, and without phylogenetic meaning. In this work, "Obsoletus ensemble" refers to the Obsoletus group and $C$. dewulfi together and includes the following species: C. obsoletus, C. scoticus, Culicoides montanus Shakirzjanova, Culicoides chiopterus (Meigen) and $C$. dewulfi. The Pulicaris ensemble includes Culicoides pulicaris (Linnaeus) and Culicoides punctatus (Meigen). As it is commonly used in the literature while authors differ in its composition, we refer to the Obsoletus group as a species group including $C$. obsoletus, C. scoticus, C. montanus and C. chiopterus. Based on the phylogenetic analysis of Schwenkenbecher et al. [42], we considered C. dewulfi as a separate species from Obsoletus group. We focused on these seven species, as they are considered to be farm-associated species [27, 29]. Culicoides imicola specimens were identified to species level by the two countries in which they were found (Spain and France). The sampling period is shown in Additional file 1: Table S1 while the number of trapping farms per country, trap type, and national protocols of the specific country are presented in Table 1.

\section{European temperature data}

We obtained daily temperature data from Europe between 1994 and 2004 from MARS-Agri4cast. As 


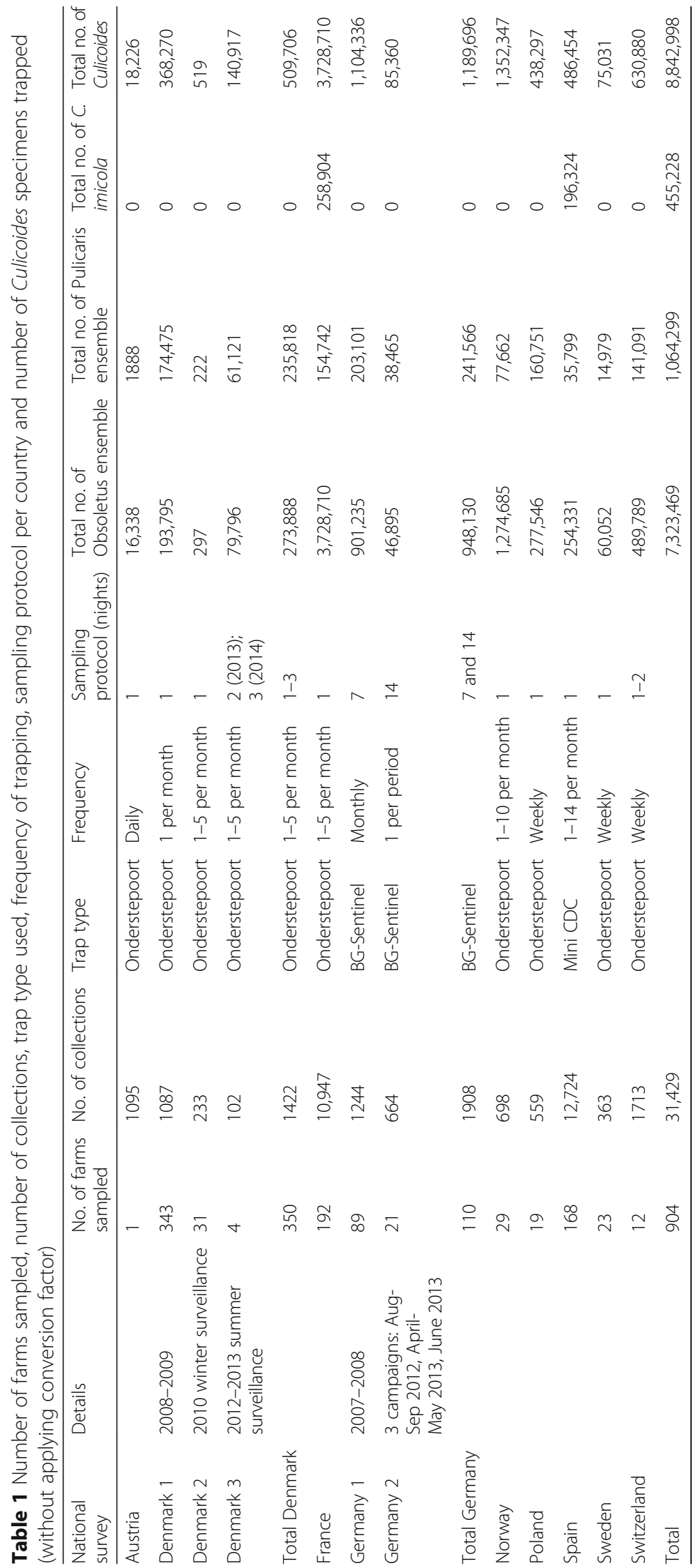


previously described by Beek [43], these data resulted from a linear interpolation of weather stations distributed across Europe into regular climate grids of $25 \times$ $25 \mathrm{~km}$.

\section{Descriptive analysis and data management}

We calculated the week number of each collection using the start date of the trapping. We defined week 1 of each year as 1st to 7 th of January. This was done to ensure that the same dates from different years were given the same week number. We calculated the weekly and monthly mean abundance of vectors for each year. Finally, we calculated the average weekly and monthly abundance for the entire seven-year period to derive estimates for an "average year".

We conducted three different analyses. In the first analysis, we divided Europe into seven latitudinal bands (A-G) of $5^{\circ}$ width, from $35^{\circ} \mathrm{N}$ to $70^{\circ} \mathrm{N}$ (Fig. 1). Latitude range $\mathrm{G}\left(>65^{\circ} \mathrm{N}\right)$ contained only two farms with just 9 observations from 4 weeks in August and September 2008, and was therefore not included in the latitudinal range analysis. To compare the seasonal variation among the seven different latitude ranges, we $\log$ transformed the trap collection data $\left[\log _{10}(x+1)\right]$ and then calculated the mean of all the trap collections for each week number and at each latitude range, based on the data for the entire 7-year period (Fig. 1). To quantify the variation of the mean abundance for each week number, we calculated the 10th and 90th percentiles. For each latitudinal range, we also calculated the weekly average of the daily minimum, mean and maximum temperatures per week for the period from 1994 to 2004, and contrasted with the Culicoides seasonal variation. We estimated the number of vectors collected in an average year within each latitudinal range by calculating the annual cumulative sum of the weekly mean abundance and multiplying this by 7 days.

In the second analysis, we calculated the average abundance on each farm for each of the 12 months $\left[\log _{10}(x+1)\right]$. We then spatially interpolated the $\log$ transformed monthly averages to create spatial abundance maps. The interpolation was done using Inverse Squared Distance Weight (IDW) and based on the 15 nearest trap locations in ArcGIS 10.1 (ESRI, Redlands, CA, USA). We created buffer zones of $200 \mathrm{~km}$ around each farm and excluded all areas beyond this limit to avoid extrapolating to unsampled areas. In addition, countries outside the area of analysis were not included in the map.

In the third analysis we examined the spatial pattern of the start of the vector season by plotting the season start date of each NUTS (nomenclature of territorial units for statistics) 3rd level polygons defined by
Eurostat (1992). NUTS is a hierarchical system used to divide up the economic territory of the EU for statistical purposes. We calculated the average start of the season for the 7-year period. The start of the season was defined as the first month in which the average monthly abundance per area polygon was equal to or higher than one specimen of $C$. imicola, and equal to or higher than 5 specimens of the Obsoletus and Pulicaris ensemble. The threshold numbers used here were based on (but not identical to) the threshold numbers defined by the European Commission to determine the start of the season [20]. While the EU thresholds are based on individual traps, we applied the thresholds to the average vector densities of all traps within a polygon. Polygons were classified as having "no data" if (i) the polygon did not have any sampled farms, (ii) if the mean abundance of the polygon did not reach the threshold during the year, or if (iii) there were no data available for the month prior the start of the season, thus making it impossible to detect whether the season might have started earlier.

\section{Results}

The trap data made available for our analyses included a total of 8,842,998 biting midges that had been collected at 904 farms between 2007 and 2013 in nine European countries. Of these, $82.8 \%$ belonged to the Obsoletus ensemble, $12.0 \%$ to the Pulicaris ensemble and $5.1 \%$ were C. imicola. Biting midges of the Obsoletus and Pulicaris ensemble were found in all countries that were sampled, while C. imicola was only found in Spain, along the southern coast of France and in Corsica.

\section{Culicoides temporal fluctuation by latitude range}

We observed a large variation in abundance in individual traps at each latitude range and at each week number, with the weekly 10th and 90th percentiles varying by a factor of 100 or more. However, when examining the average seasonal abundance, we were still able to observe two main patterns for the two species ensembles and C. imicola. First, the annual peak abundance in the Obsoletus ensemble increased gradually from Latitude A until it reached the highest weekly average peak of over 1000 vectors per night in Latitude F (Fig. 2, left column). Secondly, the period of the vector activity became increasingly shorter at higher latitudes, lasting throughout the whole year at Latitudes A and B (Fig. 2, left column), but only from week 15 (April) to week 46 (November) at Latitude F. Despite the increasingly shorter season for the Obsoletus ensemble further north, the cumulative sum of the weekly abundance steadily increased with latitude from less than 1000 Obsoletus ensemble vectors per year on average at Latitude A to 500,000 at Latitude F (Fig. 2, right column). 


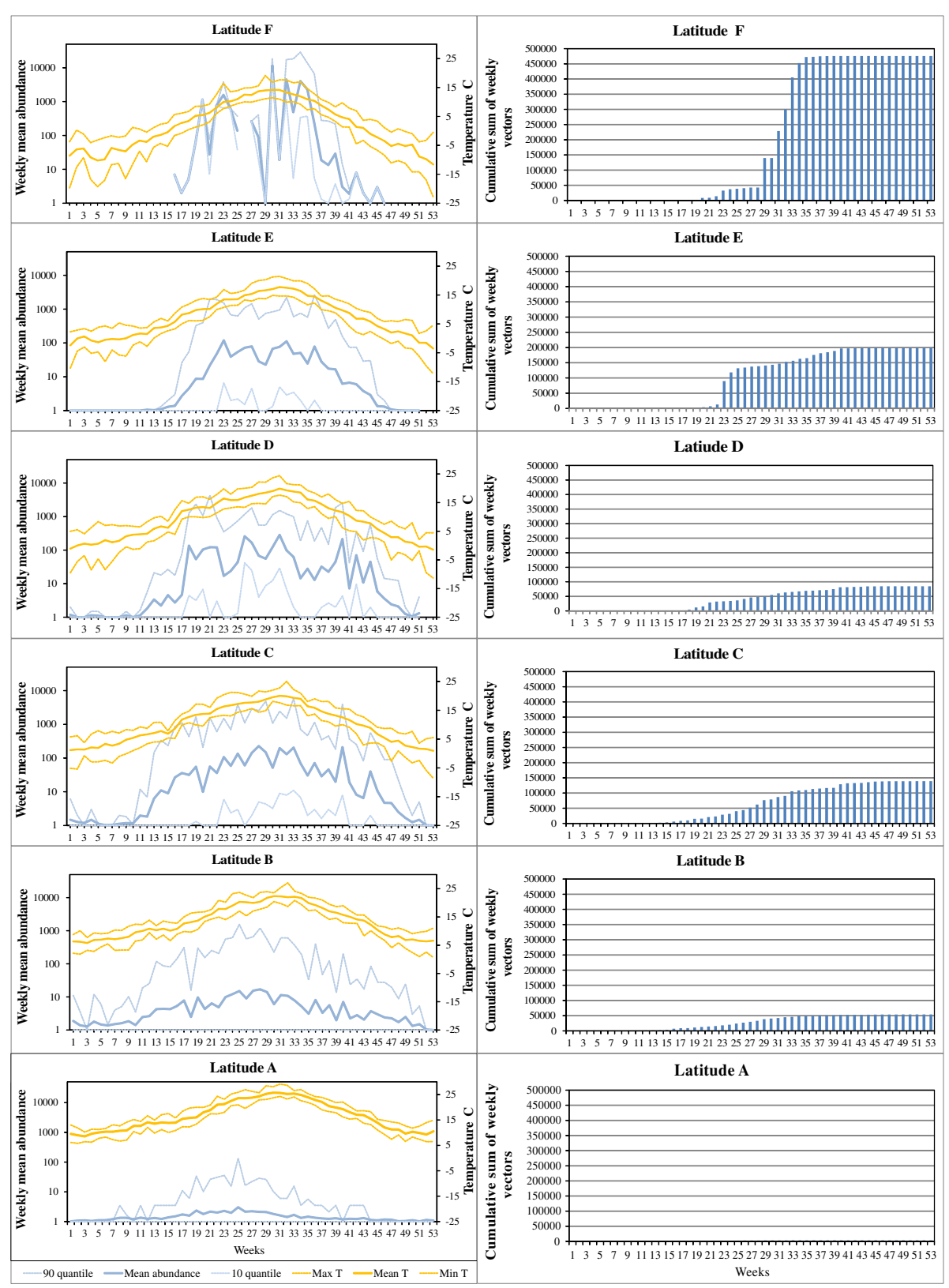

Fig. 2 Left column: Obsoletus ensemble weekly average (log scale) with 10th and 90th percentiles for an average year per latitudinal zone (A-F). Right column: cumulative weekly number of vectors per year, by latitudinal zone. The latitudinal zones ranged from southern Spain (A) to the northern Scandinavia (F)

We found a similar trend in the abundance of the Pulicaris ensemble vectors from south to north: the weekly mean abundance increased gradually from less than 5 in Latitude A to a peak weekly average of 100 in Latitude D (Fig. 3). However, in contrast to the Obsoletus ensemble, the Pulicaris ensemble abundance did not continue to increase beyond Latitude range D. In Latitude $\mathrm{F}$, there was a marked variation in abundance across weeks (varying from low abundance one week to high peaks the next week). The cumulative sum of the weekly mean of Pulicaris ensemble abundance showed a different pattern compared to the Obsoletus ensemble, with the mean accumulated number of Pulicaris ensemble vectors peaking at mid-range latitudes (Latitude D) and reaching only 41,000 vectors per year (Fig. 3, right column). This value decreased to 15,000 vectors per year further north and south at Latitudes $\mathrm{F}$ and $\mathrm{C}$, and to 1600 at Latitude A.

The duration of the season for the Pulicaris ensemble gradually decreased from Latitude B, where it lasted 


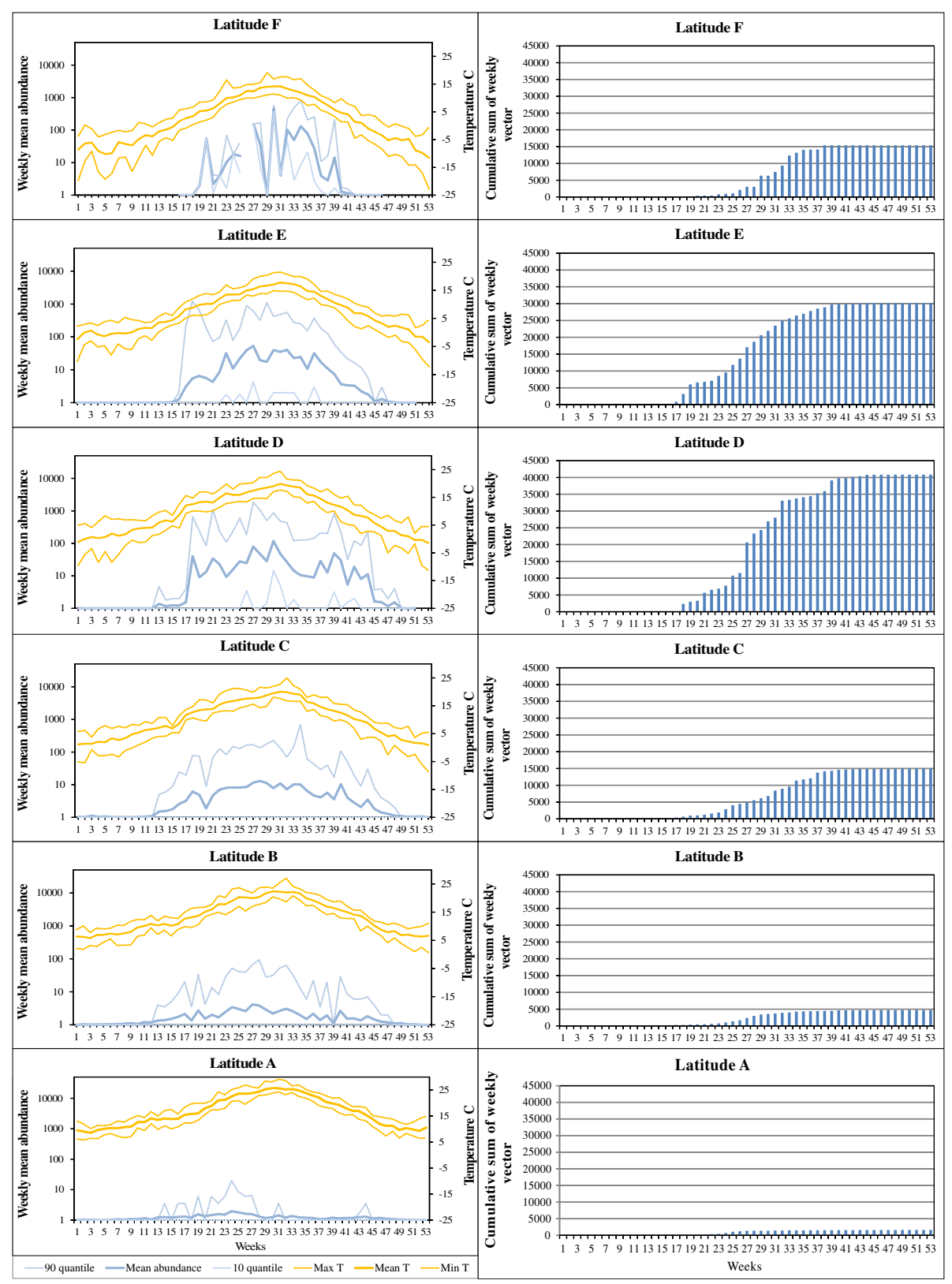

Fig. 3 Left column: Pulicaris ensemble weekly average (log scale) with 10th and 90th percentiles for an average year per latitudinal zone (A-F). Right column: cumulative weekly number of vectors per year, by latitudinal zone. The latitudinal zones ranged from southern Spain (A) to the northern Scandinavia (F)

from week 12 (April) to week 44 (October), toward Latitude $F$, where it lasted from week 18 (May) to week 41 (October). The vector season was shorter and the abundance lower for the Pulicaris ensemble than the Obsoletus ensemble at all latitude ranges. The mean temperature at the start of the vector season differed between Latitudes A and F. The season started with a mean temperature of $10{ }^{\circ} \mathrm{C}$ for the Obsoletus ensemble and $12{ }^{\circ} \mathrm{C}$ for the Pulicaris ensemble in southern latitudes, whereas the vector season started at much cooler mean temperatures $\left(1{ }^{\circ} \mathrm{C}\right.$ and $3{ }^{\circ} \mathrm{C}$, respectively) at Latitude F (Figs. 2, 3; left columns).

At Latitude A, the abundance of C. imicola increased gradually until it reached the highest mean abundance of nearly 10 vectors per night (Fig. 4). At Latitude B (comprising northern Spain and Corsica), mean abundance was very low ( $<3$ specimens at the highest peak). This was due to $C$. imicola being almost absent in northern Spain at Latitude B, so the fluctuation of the observed abundance at this latitude was mainly caused by 


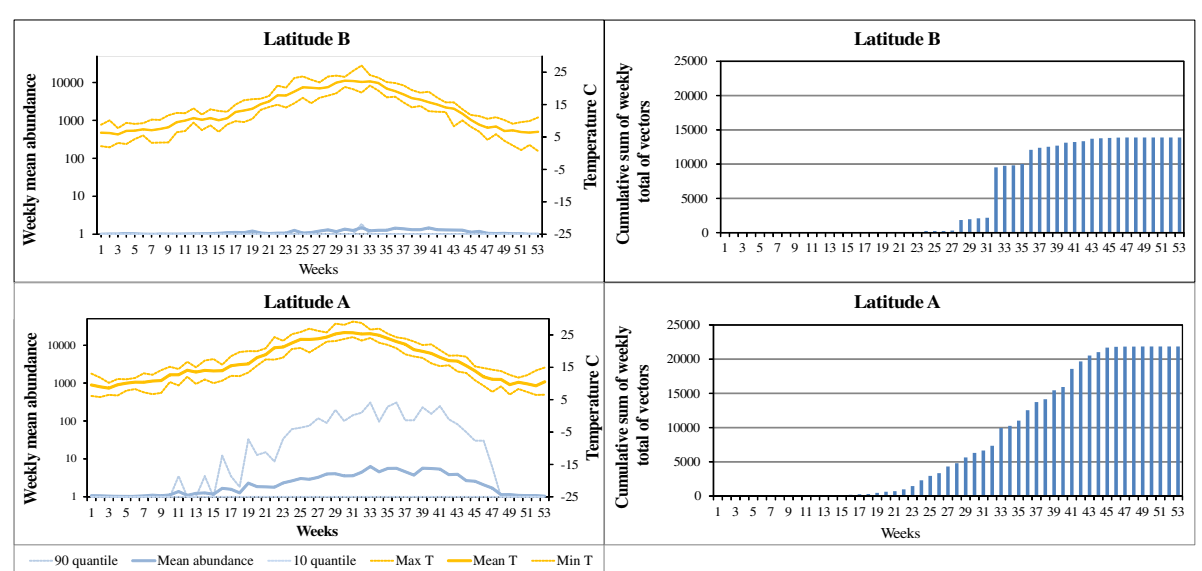

Fig. 4 Left column: C. imicola weekly average (log scale) with 10th and 90th percentiles for an average year per latitudinal zone (A-B). Right column: number of vectors per year, calculated as the cumulative sum of the weekly average multiplied by 7 , by latitudinal range

collections made in Corsica. The vector season at Latitude A lasted from week 16 (April) to week 48 (November).

\section{Abundance and interpolation maps}

We observed a large variation in monthly abundance among farms in the same region for all two ensembles and C. imicola. However, spatially interpolation the mean monthly abundance at each farm revealed regions with a higher abundance and showed systematic variation within each latitude zone (Figs. 5 and 6). The regions with the highest monthly interpolated abundance of the Obsoletus ensemble were found in France (particularly in the north-west), Germany and southern Scandinavia (especially southern Norway). During the summer period, the monthly interpolated daily abundance was often high $(1000-10,000)$ and occasionally very high $(>10,000)$ in these countries (Fig. 5). Every month, the interpolated abundance of the Pulicaris ensemble was of a lower magnitude than for the Obsoletus ensemble. During the summer months, farms with low (10-100) and medium (100-1000) abundance were often found distributed throughout the continent (with the exception of Spain), while the regions with the highest abundance were observed in Poland, Germany and Denmark with occasionally high-abundance (100010,000) farms (Fig. 6). The distribution in the high abundance regions were therefore found to be in more easterly areas for the Pulicaris ensemble compared to the Obsoletus ensemble.

The geographical areas where the Pulicaris ensemble and the Obsoletus ensemble showed the highest interpolated abundance during the summer months were generally also the areas where the species groups were observed earliest in the spring and latest in the autumn: western France for the Obsoletus ensemble, and Poland and Germany for the Pulicaris ensemble. In regions of low abundance, midges were first observed later and last observed earlier in the year (Figs. 5 and 6).

The highest abundance of C. imicola was found in Corsica, where a farm with extremely high abundance was found $(>10,000)$. In general, Spain had a medium abundance (100-1000), but high-abundance farms could occasionally be found. However, the abundance did not reach the levels seen for the Obsoletus ensemble in northern Europe (Fig. 7).

\section{Start of vector season by NUTS 3 polygon level}

We defined the start of the vector season for each NUTS 3 polygon as the first month with a mean abundance higher than or equal to one specimen for C. imicola, and higher than or equal to five specimens for the Obsoletus and Pulicaris ensembles.

According to this definition, the start of the season for the Obsoletus ensemble occurred as early as January in the west of France, some parts of Spain and Germany (Fig. 8) and as late as June in Scandinavia. In France, there was a clear spatial pattern where the Obsoletus ensemble season started early (January) in the west, and 2 to 3 months later in the east (March-April). In some provinces in Spain, the season started late (April-June).

The start of the vector season for the Pulicaris ensemble showed a spatial pattern similar to the Obsoletus ensemble, with a south-to-north gradient, where southern latitudes had an earlier start of the season (January to April in Spain and France) compared to northern latitudes (May to September in the Scandinavian countries). The start of the season for the Pulicaris ensemble occurred as early as January in some parts of Spain, Germany and Corsica, but generally occurred from March-April, 2 months later than for the Obsoletus ensemble (Fig. 9). In France, we observed the same pattern 


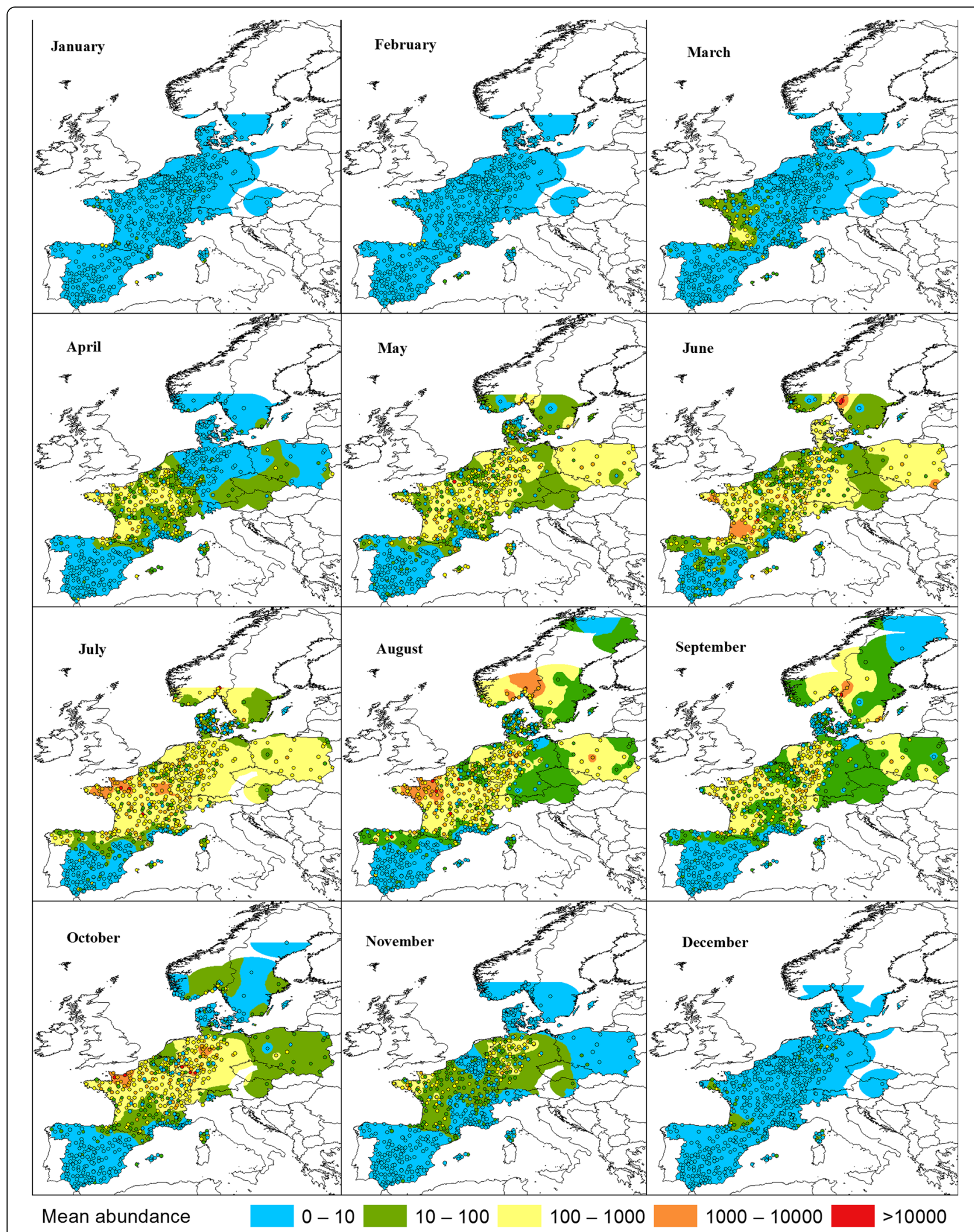

Fig. 5 Obsoletus ensemble monthly mean abundance. Dots show observed monthly mean abundance at sampled farms. Spatially interpolated abundance is shown in color. Interpolation values are displayed on the same scale as the observed abundance 


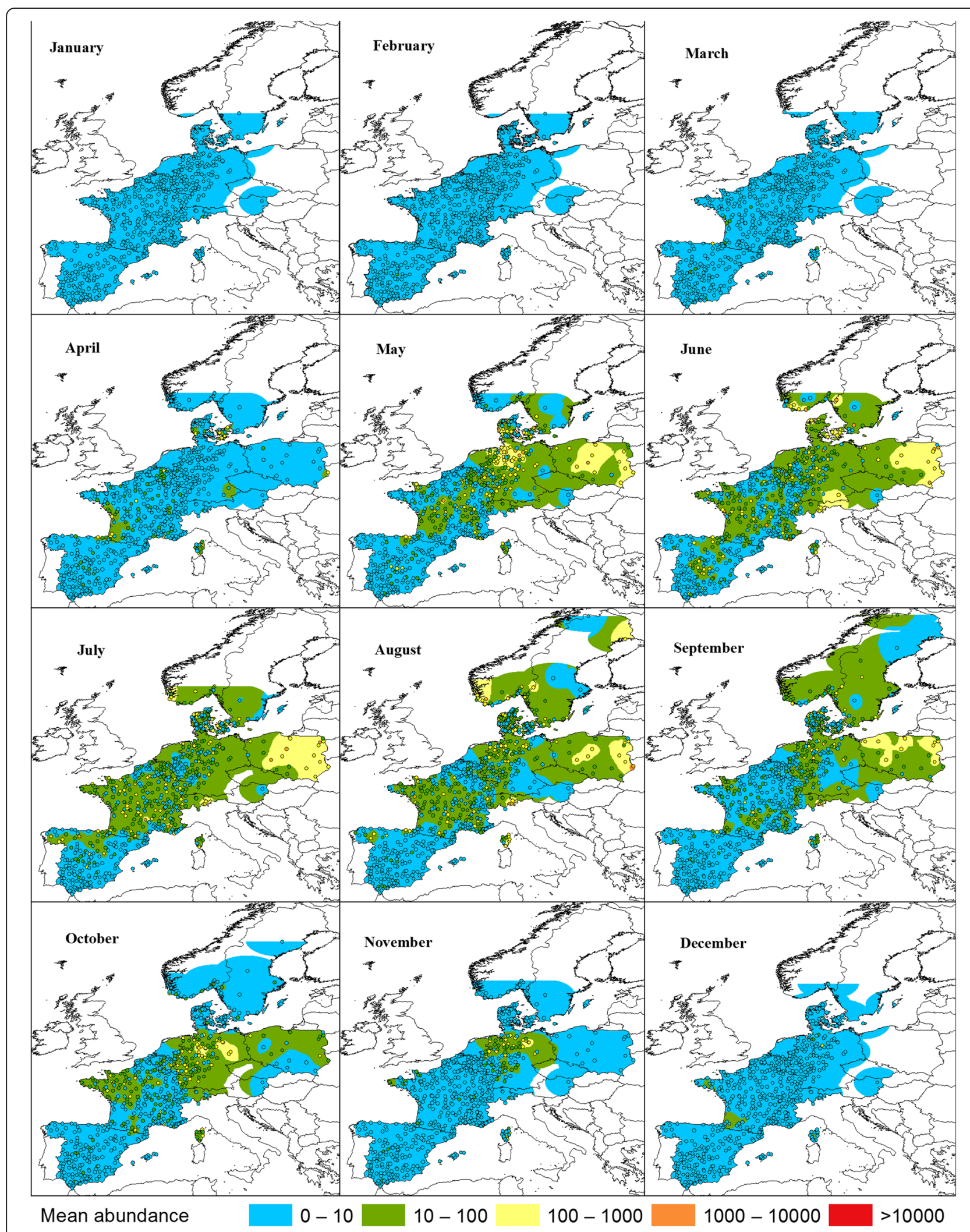

Fig. 6 Pulicaris ensemble monthly mean abundance. Dots indicate observed monthly mean abundance in sampled farms. Spatially interpolated abundance is shown in color. Interpolation values are displayed on the same scale as the observed abundance 


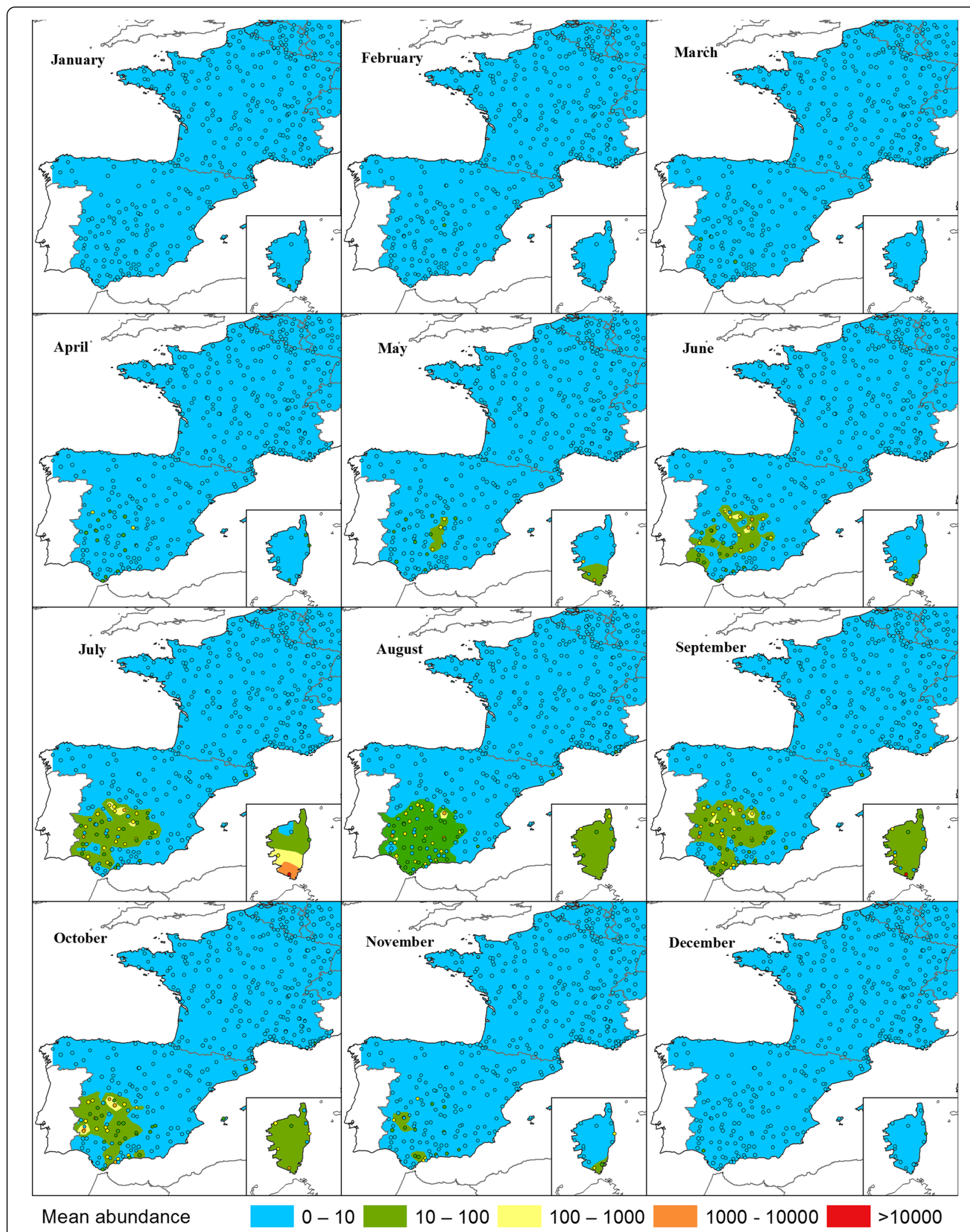

Fig. 7 C. imicola monthly mean abundance. Dots indicate observed monthly mean abundance in sampled farms. Spatially interpolated abundance is shown in color. Interpolation values are displayed on the same scale as the observed abundance 


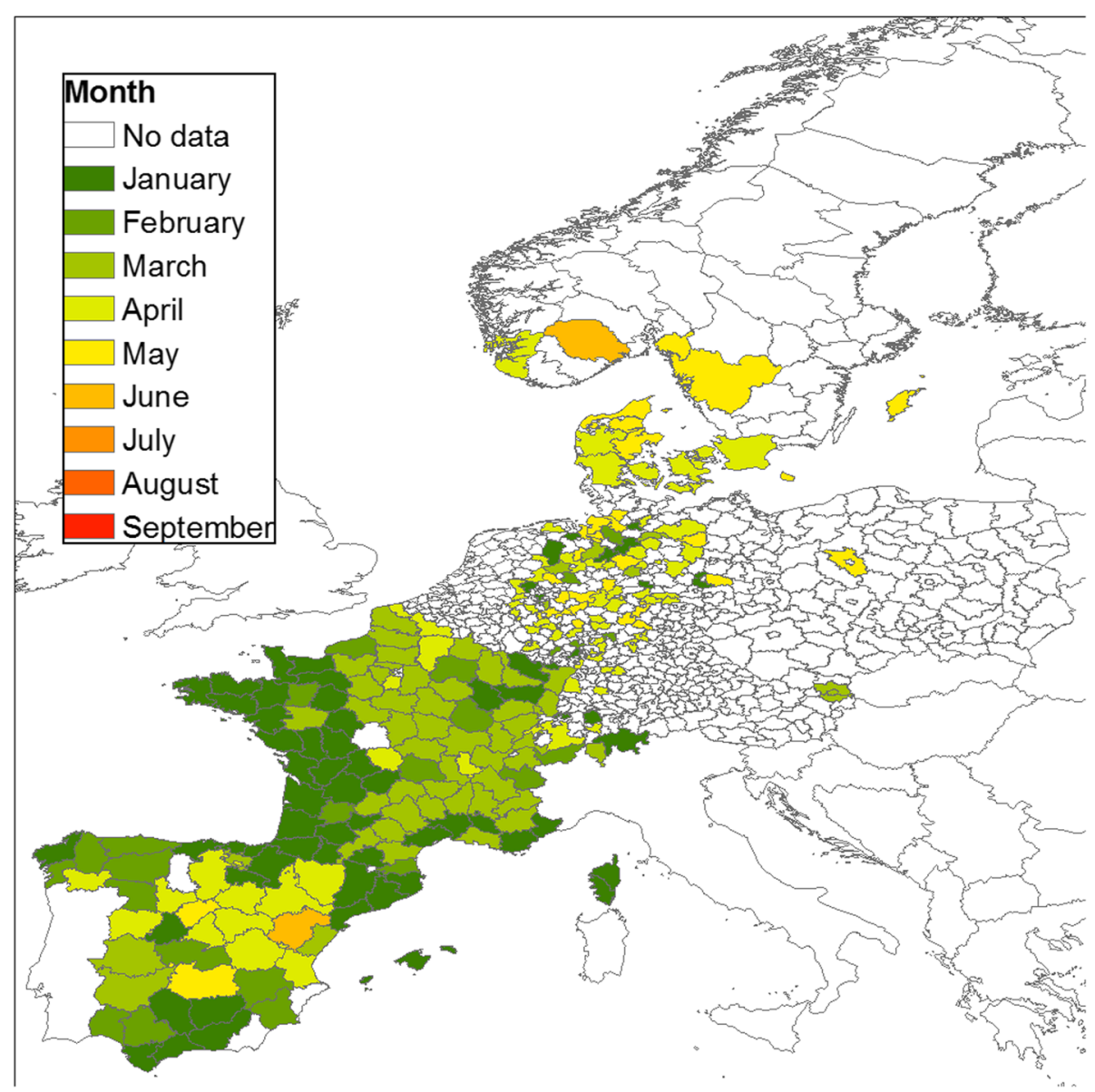

Fig. 8 Start of the vector season for the Obsoletus ensemble by NUTS 3 polygons and by month

found for the Obsoletus ensemble, where the start of the season for the Pulicaris ensemble occurred earlier (March) in the west compared to the eastern parts of the country (April).

Culicoides imicola was only recorded in Spain and France. The vector season started as early as January in southern Spain and on Corsica, while in the northern provinces of Spain, it started 5 months later (Fig. 10). However, there were also two provinces in the south of Spain where the average abundance per polygon did not reach the threshold value of one until June-August.

\section{Discussion}

The descriptive analysis presented here is based on the most extensive Culicoides dataset created for Europe to date, and represents the first combined description of Culicoides abundance and distribution for a large part of Europe. The data were gathered from a $4000 \mathrm{~km}$ long transect from southern Spain to the Arctic Circle in Sweden, with the most easterly collection sites in Poland. The primary aim of this descriptive analysis was to identify and quantify major geographical patterns and seasonal trends in the abundance of key Culicoides vector groups. The focus of the analysis was to identify patterns and trends important for decision making to prevent, surveillance and control of Culicoides-borne pathogens.

Specimens of the Obsoletus and Pulicaris ensemble were found in all of the countries sampled. The Obsoletus ensemble was ten times more abundant than the Pulicaris ensemble. Both groups have a Palaearctic distribution, and are widely distributed in Europe [13, 44-47]. However, the abundance of both ensembles and C. imicola varied dramatically among farms in the same region sampled during the same period, often showing a 100 -fold difference between the 10th and the 90th percentile in terms of the weekly trap abundance within each latitude group. Nevertheless, distinct spatial and temporal patterns arose under the three analyses conducted in this work.

Examining the weekly data for the seven latitude ranges, we found that the mean weekly abundance of both ensembles and C. imicola varied dramatically along the south-north transect. It is interesting to note that the annual number of the Obsoletus ensemble gradually increased toward northern latitudes, despite the vector 


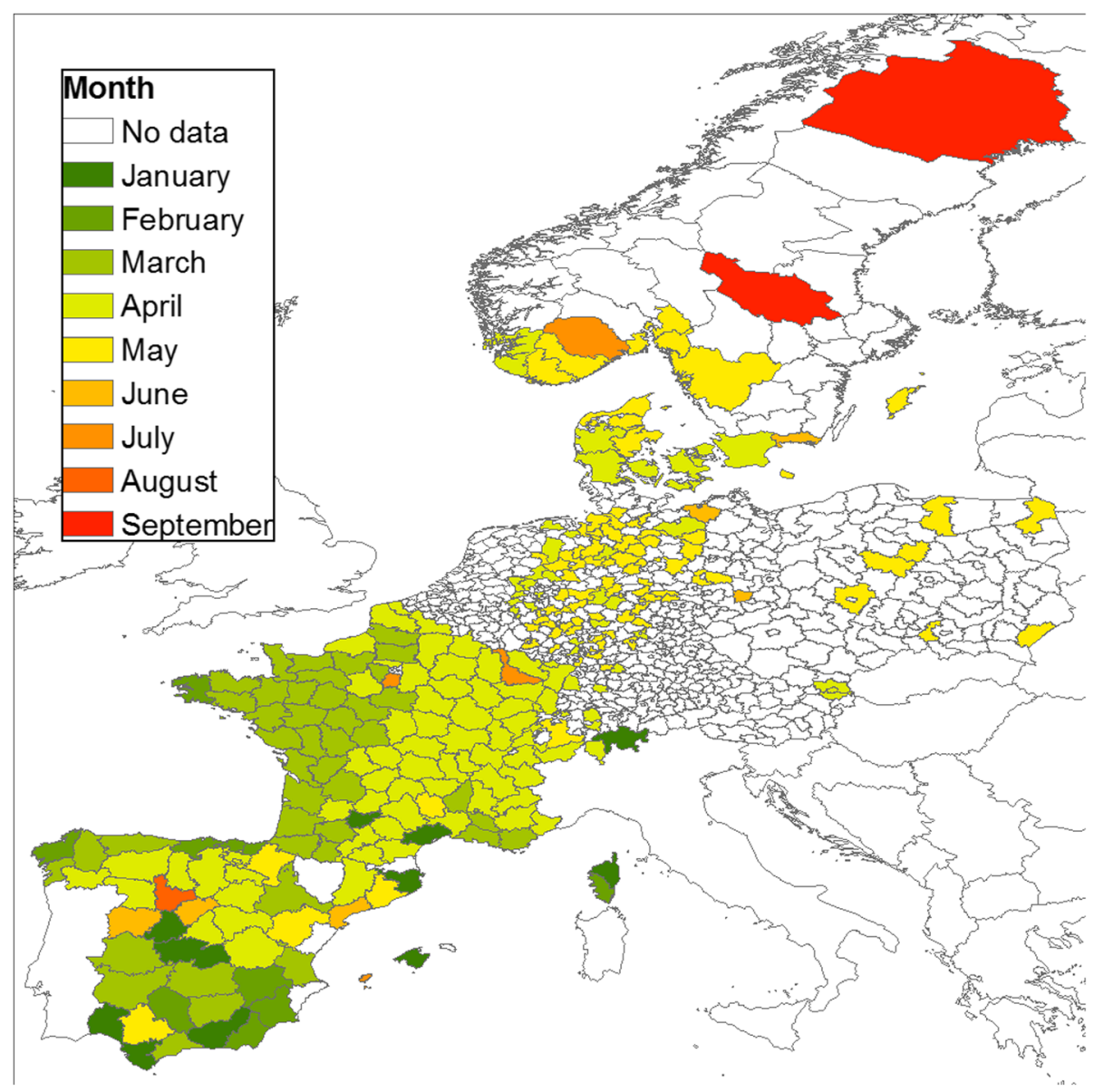

Fig. 9 Start of the vector season for the Pulicaris ensemble by NUTS 3 polygons and by month

season gradually shortening by three months from southern Spain to mid Scandinavia. This suggests that the Obsoletus ensemble is better adapted to the northern European climate in the environments surrounding farms. The Pulicaris ensemble appear better adapted to central Europe, and C. imicola to southern Europe, in the dry Mediterranean regions characterized by hot summers [47]. Although in relative terms, the Pulicaris ensemble (C. pulicaris and $C$. punctatus) was more abundant in central Europe and the Obsoletus ensemble (composed of C. obsoletus, C. scoticus, C. montanus and C. chiopterus.) was more abundant in northern Europe, the Obsoletus ensemble was still more abundant than the Pulicaris ensemble at all latitudes.

To further explore the spatial abundance patterns, we interpolated the mean monthly abundance for each calendar month. We found areas of high abundance peaks for the Obsoletus ensemble in north-western France, which is in agreement with previous studies that also reported high numbers of Obsoletus ensemble specimens in France [9, 22, 23]. The Obsoletus ensemble was also found in high abundance in most parts of Germany, where similar findings have been reported by many other authors [14, 19, 24, 47, 48]. Regarding the highabundance areas found in Scandinavia in this study, these were partly driven by farms with an extremely high abundance; for example, two farms in southern Norway had more than 80,000 specimens per night (data not shown). Although the monthly mean data were $\log _{10}$ transformed before interpolation in order to reduce the impact of single sites of very high abundance, these high abundance farms from Norway still influenced the observed regional pattern. These high abundance records exceeded in great magnitude, the C. obsoletus/C. scoticus abundance previously reported in Sweden by Ander et al. [33] (> 5000 specimens in suitable months). Further collections in southern Norway are needed to determine how often the Obsoletus ensemble occurs at these extremely high numbers. The traps with the highest abundance of the Pulicaris ensemble were located in Germany and Poland, with a lower abundance in France and Scandinavia [14, 49, 50]. In general, the Pulicaris ensemble showed a spatial pattern with a relatively more easterly distribution compared to the Obsoletus 


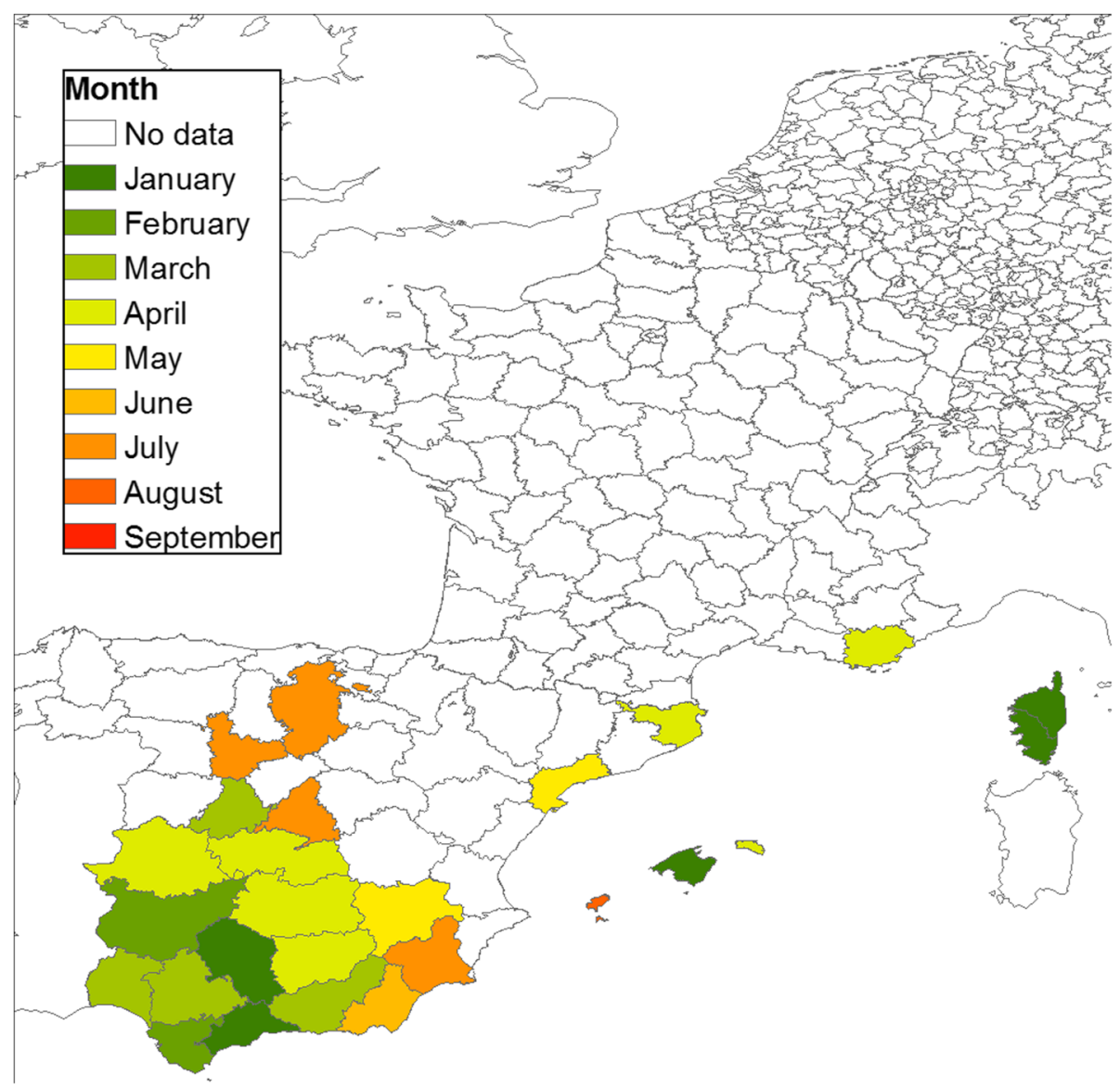

Fig. 10 Start of the vector season for C. imicola by NUTS 3 polygons and by months

ensemble. The distribution of the regions with the highest $C$. imicola abundance were in accordance with the known C. imicola distribution in Europe [9, 21, 22, 47]. Based on the interpolated monthly abundance maps, each vector group tended to appear early in the traps situated in areas that reached the highest abundance during summer, and were observed latest in the autumn. When the monthly maps are considered as a time series, the Obsoletus ensemble appears to start in western France, to increase in abundance and spread north and east until the end of August, when they retract to western France again. The Pulicaris ensemble appears to start in traps in Poland and, to a certain extent, the south-western areas of France, to grow in number and spread north and east before retracting again after $\mathrm{Au}$ gust, to be observed last in Poland, northern Germany and western France. For $C$. imicola, the same phenomenon of areas with a strong spatial correlation between early appearance, peak abundance and a long vector season was seen in southern Corsica and southeastern Spain.

The Culicoides abundance analysed in this study is exclusively based on the abundance observed on farms.
The spatial abundance derived by interpolation therefore represents the abundance given the presence of a farm, and cannot be interpreted as an estimate of abundance in "non-farm" habitats, e.g. natural areas. Interpolation is used as tool to visualize the average abundance on farms in a larger area. To produce more detailed maps of vector abundance in future, a predictive modelling approach based on environmental and climate predictor variables will be necessary.

We analysed the start of the vector season for polygon areas in the participating countries. The European Commission currently defines the start of the vector season as the week during which the number of parous females exceeding a certain threshold (five for C. obsoletus and one for C. imicola) are caught by any trap in an area [20]. However, because there is a large variation in abundance among traps in the same area, the probability of finding a trap with an abundance exceeding the threshold will increase with the number of traps operated in the area. As a result, the vector season will tend to start earlier in regions with a higher number of traps. In this analysis, where the density of traps varies geographically, we used a more robust approach to define the start of 
the vector season. We took into account the number of traps in a geographical area by calculating the mean trap abundance and using five vectors per trap as the cutoff (one female per trap for C. imicola). For the Obsoletus ensemble, there was not a clear pattern in Spain, where the vector season started at different months in different polygons. Nevertheless, there was a south-north trend starting in southern France and continuing to northern Scandinavia. The length of the vector season decreased by three months at northern latitudes where the period of climatic conditions suitable for midge development is shorter. Versteirt et al. [51] investigated the start and end of the vector season for C. imicola and C. obsoletus/C. scoticus on a continental scale in Europe. Their results also showed a south-north pattern in the start and length of the vector season. However, for C. imicola, our observed data suggested that the start of the season would occur earlier in the year (January-February) compared to their results where the season started in March. The start of the Pulicaris ensemble season had a similar pattern to the Obsoletus ensemble, starting two months later at higher latitudes; however, the start of the season seems to be more homogenous across latitudes compared to Obsoletus ensemble. We found the start of the season pattern for C. imicola is similar to previous results [51], with the only difference that in our study the vector season started as early as January on Corsica and in some provinces of Spain, which we interpret as areas with $C$. imicola vector activity all year round. The start of the season occurred later in the year in polygons where the peak Culicoides abundance in summer was low, as the density gradually increased and the cutoff defining the start of the vector season was reached later than in areas with a high peak abundance. For example, the Pulicaris ensemble activity started as late as September in northern Sweden, despite the first individual being observed much earlier. The start of the vector season is therefore highly sensitive to the vector abundance threshold selected to define it.

The latitude range analysis showed that the vector season for both the Obsoletus and Pulicaris ensembles started in the southern latitude range at an average mean temperature of $10{ }^{\circ} \mathrm{C}$ and $12{ }^{\circ} \mathrm{C}$, respectively. However, at northern latitudes, the season started before spring temperatures rose, meaning that the vector season started at mean temperatures of just $1{ }^{\circ} \mathrm{C}$ and $3{ }^{\circ} \mathrm{C}$. This suggests an adaptation of the vector population to the cooler climates in northern Europe. Early EU regulations suggested that vector-free periods may be defined by a specific temperature threshold when vector surveillance data were lacking [46]. Yet the start of the vector season at successively lower temperatures toward northern latitudes found in the present study demonstrates that such a simple temperature criterion alone would be a poor proxy for the start of the vector season, and would risk the prediction of an unrealistically long vector-free season in northern Europe.

One country used CDC traps (Spain) and one used BG-sentinel traps (Germany), while the rest used Onderstepoort traps. Previous studies compared the efficacy of different trap types, and the results showed that the number of midges collected varied according to the type used. It was reported that Onderstepoort traps collected more specimens than Mini CDC and BG-sentinel traps [35-37]. We attempted to adjust for this using published trap comparisons, but the relative efficiency of each type trap vary considerably. However, this uncertainty in trap efficiency is likely to be of a smaller magnitude than the variation in abundance within the spatial patterns which is of at least a 10 to 100 fold magnitude. The used trap conversion factor is therefore unlikely to have affected the identified overall spatial patterns identified here.

Light traps are most efficient when collection nights are dark $[10,52]$ and trapping in northern latitudes may therefore be less effective because nights during the summer season are shorter than in southern Europe [53]. The use of light traps in this study may therefore have underestimated the vector abundance at higher latitudes during the summer period.

We here focus on estimating the host seeking vector population. The vectors collected in light traps near stables and animal resting sites are likely to be predominantly host-seeking, while vectors that are already bloodfed are less likely to be collected in traps. The results from this analysis cannot directly be used for estimating the total vector population consisting of both host seeking and non-host seeking vectors. Because the blood meal digestion time in Culicoides is relatively slower at low temperatures [54], the proportion of the Culicoides population digesting blood and developing eggs and not attracted to traps may therefore be relatively larger at low temperatures. Due to the increasingly lower temperatures toward the north of the transect, the total vector population estimated from trap collections at higher latitudes, will be underestimated compared to the total vector population estimated from trap collections in southern Europe unless the blood meal developing time is taken into account.

Females of the species belonging to the Obsoletus group are difficult to separate based on morphological characters [13, 18, 38-41, 55] and therefore they are often grouped into the Obsoletus group or complex. The same occurs with the species of the Pulicaris group which are often merged into the Pulicaris group [25, 31, $56,57]$. Aggregating species into groups might represent a problem for identifying accurate temporal and spatial 
patterns, as different species from the same group might exhibit different seasonal trends [58, 59]. The seasonal fluctuation of individual species of the Obsoletus group remains unknown. However, Searle et al. [27] analysed the phenology (start, end and duration of the vector season) of the male specimens for each species and the authors did not find a significant difference between the start and the end of season among the species. Nevertheless they found the length of the season period was different among them. Analyses regarding temporal fluctuation at species level of the Obsoletus group would be necessary as the species might present different temporal fluctuation patterns undetected when the species are grouped. Little is known about potential differences in vector competence for BTV for individual species of the Obsoletus and Pulicaris ensemble [11]. A study on the subject includes Carpenter et al. [60] who analysed vector competence for the Obsoletus group in the UK. Vector competence at species level of the Obsoletus group for SBV can be found in [60], Balenghien et al. [61] and Ségard et al. [62]. In this work, despite analyzing the data at ensemble level, we consider that the identified patterns and trends identified here still represent a useful and relevant overview of transmission potential in Europe.

\section{Conclusions}

This is the first report in which a dataset this size and covering a large part of Europe has been analysed. We identified and quantified the main mean spatial and temporal differences of three Culicoides species groups. Understanding the spatial and seasonal patterns of key vector groups or species facilitates the planning of preventive strategies and allows the development of more cost-effective vector and disease surveillance programmes by veterinary authorities in the European Union. The monthly abundance of the Obsoletus ensemble increased gradually from northern Spain to mid Scandinavia. The vector season also became increasingly shorter toward the north, starting three months later in mid Scandinavia compared to southern Spain. Nevertheless, the annual accumulated abundance of the Obsoletus ensemble increased steadily with latitude to 500,000 vectors per trap per year in mid Scandinavia. The Pulicaris ensemble was more frequent in central Europe, peaking in Germany and Poland with about 40,000 vectors per year, and with a more easterly distribution compared to the Obsoletus ensemble. For each of the species groups, there were areas in which the vectors appeared early, reached the highest mean peak abundances and lasted the longest. The Obsoletus ensemble was more abundant and had a longer season than the Pulicaris ensemble, whereas $C$. imicola appeared as a strictly southern species with a long vector season but with an abundance level that did not reach the peak abundance observed for the Obsoletus ensemble. This study suggests that future collaboration and data sharing between European countries may further improve our understanding of the spatio-temporal abundance of Culicoides vectors.

\section{Additional file}

Additional file 1: Table S1. Monthly availability of Culicoides trap data in the participating countries during the selected seven-year study period (20072013). X symbol indicates months when data were available. (XLSX 12 kb)

\section{Abbreviations}

BTV: bluetongue virus; NUTS: Nomenclature of territorial units for statistics; SBV: Schmallenberg virus

\section{Acknowledgments}

We would like to thank the Direction générale de l'alimentation from the French Ministry in charge of agriculture for funding and the Directions départementales de la protection des populations for their support in collecting the biting midges during the survey. We thank the Swiss Food Safety and Veterinary Office and the Vet-Austria project for financial support to the Swiss and Austrian partners, respectively. We also thanks the Ministerio de Agricultura y Pesca, Alimentación y Medio Ambiente for providing data about the national surveillance of Culicoides in Spain and the MARS-Agri4cast at the Institute for Environment and Sustainability, European Commission, for kindly providing temperature data of Europe.

Funding

This study was funded by the EMIDA ERA-NET-supported project VICE (Vector-borne Infections: risk-based and Cost-Effective surveillance systems). Culicoides data from Germany were partly collected within the German part of the VICE project funded by EMIDA ERA-NET through the Federal Office for Agriculture and Food (grant no. 314-06.01-2811ERA248).

\section{Availability of data and materials}

The national surveillance and research data that support the findings of this study are available from Spain: Miguel Ángel Miranda Chueca, France: Thomas Balenghien, Germany: Jörn Gethmann, Denmark: Rene Bødker, Sweden: Anders Lindström, Norway: Petter Hopp, Poland: Magdalena Larska, Austria: Katharina Brugger, Switzerland: Alexander Mathis but restrictions apply to the availability of these data, which were used under license for the current study, and so are not publicly available. Data are, however, available from the authors upon reasonable request and with permission of the national surveillance programmes of each country.

\section{Authors' contributions}

ACC analysed the data and drafted the manuscript. RB planned the original study, contributed to analysis and drafting the manuscript. LJK contributed to analysis and drafting the manuscript. CK, HS, SAN, AS, GA, AL, JC, RL, SS, $E K, J G, F C, M L, I H, S S, P H, K B, F R, T B, C G, I R, X A, J L, J C D, B M, D D, M L S, R V, B S$, MAMC, CB, JL, RE, AM and WT: discussed and identified preliminary national data, negotiated data access with national surveillance authorities and research projects, jointly discussed the taxonomic and spatial resolution for analysis and identified, and selected and extracted the final data and relevant variables meeting the criteria for the joint database, wrote the protocol summaries and commented on the analysis results and edited the manuscript. All authors read and approved the final manuscript.

Ethics approval and consent to participate Not applicable.

Consent for publication

Not applicable. 


\section{Competing interests}

The authors declare that they have no competing interests.

\section{Publisher's Note}

Springer Nature remains neutral with regard to jurisdictional claims in published maps and institutional affiliations.

\section{Author details}

'Division for Diagnostics and Scientific Advice, National Veterinary Institute, Technical University of Denmark (DTU), Copenhagen, Denmark. ${ }^{2}$ Department of Agroecology - Entomology and Plant Pathology, Aarhus University, Aarhus, Denmark. ${ }^{3}$ Department of Science and Environment, Roskilde University, Roskilde, Denmark. ${ }^{4}$ Department of Applied Mathematics and Computer Science, Technical University of Denmark (DTU), Copenhagen, Denmark. ${ }^{5}$ National Veterinary Institute (SVA), Uppsala, Sweden. ${ }^{6}$ Bernhard Nocht Institute for Tropical Medicine, WHO Collaborating Centre for Arbovirus and Hemorrhagic Fever Reference and Research National Reference Centre for Tropical Infectious Diseases, Hamburg, Germany. ${ }^{7}$ Department of Biology and Environmental Sciences, Carl von Ossietzky University, Oldenburg, Germany. ${ }^{8}$ Institute of Epidemiology, Friedrich Loeffler Institute, Greifswald, Germany. ${ }^{9}$ Department of Virology, National Veterinary Research Institute, Pulawy, Poland. ${ }^{10}$ Norwegian Veterinary Institute, Oslo, Norway. ${ }^{11}$ Institute for Veterinary Public Health, Vetmeduni, Vienna, Austria. ${ }^{12}$ CIRAD, UMR ASTRE, F-34398 Montpellier, France. ${ }^{13}$ Institute of Parasitology and Tropical Pathology of Strasbourg, EA7292, Université de Strasbourg, Strasbourg, France. ${ }^{14}$ EID Méditerranée, Montpellier, France. ${ }^{15}$ Laboratory of Zoology, University of the Balearic Islands, Palma de Mallorca, Spain.

${ }^{16}$ Department of Animal Pathology, University of Zaragoza, Zaragoza, Spain.

${ }^{17}$ Institute of Parasitology, University of Zürich, Zürich, Switzerland. ${ }^{18}$ Avia-GIS NV, Zoersel, Belgium.

\section{Received: 5 December 2017 Accepted: 12 February 2018}

\section{Published online: 27 February 2018}

\section{References}

1. Carpenter S, Wilson A, Mellor PS. Culicoides and the emergence of bluetongue virus in northern Europe. Trends Microbiol. 2009;17:172-8.

2. Carpenter S, Groschup MH, Garros C, Felippe-Bauer ML, Purse BV. Culicoides biting midges, arboviruses and public health in Europe. Antivir Res. 2013; 100:102-13.

3. Rushton J, Economic LN. Impact of bluetongue: a review of the effects on production. Vet Ital. 2015;51:401-6.

4. Wilson AJ, Mellor PS. Bluetongue in Europe: past, present and future. Philos Trans R Soc B. 2009:364:2669-81.

5. Zientara S, Sánchez-Vizcaíno JM. Control of bluetongue in Europe. Vet Microbiol. 2013;165:33-7.

6. Rasmussen LD, Kristensen B, Kirkeby C, Rasmussen TB, Belsham GJ, Bødker R, et al. Culicoids as vectors of Schmallenberg virus. Emerg Infect Dis. 2012;18: 1204-6.

7. Mellor PS, Boned J, Hamblin C, Graham S. Isolations of African horse sickness virus from vector insects made during the 1988 epizootic in Spain. Epidemiol Infect. 1990;105:447-54.

8. Pinior B, Brugger K, Kofer J, Schwermer H, Stockreiter S, Loitsch A, et al. Economic comparison of the monitoring programmes for bluetongue vectors in Austria and Switzerland. Vet Rec. 2015;176:464.

9. Venail R, Balenghien T, Guis H, Tran A, Setier-Rio M-L, Delécolle J-C, et al. Assessing diversity and abundance of vector populations at a national scale: example of Culicoides surveillance in France after bluetongue virus emergence. In: Mehlhorn H, editor. Arthropods as vectors of Emerging Diseases. Heidelberg: Springer-Verlag; 2012. p. 77-102.

10. Carpenter S, Szmaragd C, Barber J, Labuschagne K, Gubbins S, Mellor P. An assessment of Culicoides surveillance techniques in northern Europe: have we underestimated a potential bluetongue virus vector? J Appl Ecol. 2008; 45:1237-45.

11. Savini G, Goffredo M, Monaco F, Di Gennaro A, Cafiero MA, Baldi L, et al. Bluetongue virus isolations from midges belonging to the Obsoletus complex (Culicoides, Diptera: Ceratopogonidae) in Italy. Vet Rec. 2005;157: 133-9.

12. De Liberato C, Scavia G, Lorenzetti R, Scaramozzino P, Amaddeo D, Cardeti $\mathrm{G}$, et al. Identification of Culicoides obsoletus (Diptera: Ceratopogonidae) as a vector of bluetongue virus in central Italy. Vet Rec. 2005;156:301-4.
13. Caracappa S, Torina A, Guercio A, Vitale F, Calabrò A, Purpari G, et al. Identification of a novel bluetongue virus vector species of Culicoides in Sicily. Vet Rec. 2003;153:71-4.

14. Clausen PH, Stephan A, Bartsch S, Jandowsky A, Hoffmann-Köhler P, Schein $E$, et al. Seasonal dynamics of biting midges (Diptera: Ceratopogonidae, Culicoides spp.) on dairy farms of central Germany during the 2007/2008 epidemic of bluetongue. Parasitol Res. 2009;105:381-6.

15. Wilson a CS, Gloster J, Mellor P. Re-emergence of bluetongue in northern Europe in 2007. Vet Rec. 2007;161:487-9.

16. Sperlova A, Zendulkova D. Bluetongue: a review. Vet Med (Praha). 2011;56:430-52

17. Meiswinkel R, Baldet T, de Deken R, Takken W, Delécolle J-C, Mellor PS. The 2006 outbreak of bluetongue in northern Europe - the entomological perspective. Prev Ve Med. 2008;87:55-63.

18. Nolan DV, Carpenter S, Barber J, Mellor PS, Dallas JF, Mordue Luntz AJ, et al. Rapid diagnostic PCR assays for members of the Culicoides obsoletus and Culicoides pulicaris species complexes, implicated vectors of bluetongue virus in Europe. Vet Microbiol. 2007;124:82-94.

19. Vorsprach B, Meiser CK, Werner D, Balczun C, Schaub GA. Monitoring of Ceratopogonidae in southwest Germany. Parasitol Res. 2009;105:337-44.

20. European Commission. EC 1266/2007. Off J Eur Union. 2007; L 283 of 27.10. 2007:37-52.

21. Calvete C, Miranda MA, Estrada R, Borras D, Sarto i, Monteys V, Collantes F, et al. Spatial distribution of Culicoides imicola, the main vector of bluetongue virus, in Spain. Vet Rec. 2006;158:130-1.

22. Balenghien T, Garros C, Mathieu B, Allène X, Gardes L, Rakotoarivoany I, et al. La surveillance des Culicoides en France. Bull Epidémiol Santé Anim Aliment. 2010;35:8-9.

23. Balenghien T, Delécolle J, Rakotaoarivony I. Bluetongue - report on entomological surveillance in France in 2010. Bull Epidémiol Santé Anim Aliment. 2010;46:26-31.

24. Mehlhorn H, Walldorf V, Klimpel S, Schaub G, Kiel E, Focke R, et al. Bluetongue disease in Germany (2007-2008): monitoring of entomological aspects. Parasitol Res. 2009;105:313-9.

25. Goffredo M, Conte A, Distribution MR. Abundance of Culicoides imicola, Obsoletus complex and Pulicaris complex (Diptera: Ceratopogonidae) in Italy. Vet Ital. 2004;40:270-3.

26. Brugger K, Köfer J, Rubel F. Outdoor and indoor monitoring of livestockassociated Culicoides spp. to assess vector-free periods and disease risks. BMC Vet Res. 2016;12:88.

27. Searle KR, Barber J, Stubbins F, Labuschagne K, Carpenter S, Butler A, et al Environmental drivers of Culicoides phenology: how important is speciesspecific variation when determining disease policy? PLoS One. 2014;9: e111876.

28. Acevedo P, Ruiz-Fons F, Estrada R, Márquez AL, Miranda MA, Gortázar C, et al. A broad assessment of factors determining Culicoides imicola abundance: modelling the present and forecasting its future in climate change scenarios. PLoS One. 2010;5:e14236.

29. Kaufmann C, Steinmann IC, Hegglin D, Schaffner F, Mathis A. Spatiotemporal occurrence of Culicoides biting midges in the climatic regions of Switzerland, along with large scale species identification by MALDI-TOF mass spectrometry. Parasit Vectors. 2012;5:246.

30. Kaufmann C, Schaffner F, Mathis A. Monitoring von Gnitzen (Culicoides spp.), den potentiellen Vektoren des Blauzungenkrankheitsvirus, in den 12 Klimaregionen der Schweiz. Schweiz Arch Tierheilkd. 2009;151:205-13.

31. Brugger K, Rubel F. Bluetongue disease risk assessment based on observed and projected Culicoides obsoletus spp. vector densities. PLoS One 2013;8: e60330.

32. Nielsen SA, Nielsen BO, Chirico J. Monitoring of biting midges (Diptera: Ceratopogonidae: Culicoides Latreille) on farms in Sweden during the emergence of the 2008 epidemic of bluetongue. Parasitol Res. 2010;106: 1197-203.

33. Ander M, Meiswinkel R, Chirico J. Seasonal dynamics of biting midges (Diptera: Ceratopogonidae: Culicoides), the potential vectors of bluetongue virus, in Sweden. Vet Parasitol. 2012;184:59-67.

34. Larska M, Lechowski L, Grochowska M, Żmudziński JF. Detection of the Schmallenberg virus in nulliparous Culicoides obsoletus/scoticus complex and C. punctatus - the possibility of transovarial virus transmission in the midge population and of a new vector. Vet Microbiol. 2013;166:467-73.

35. del Río R, Monerris M, Miquel M, Borràs D, Calvete C, Estrada R, et al. Collection of Culicoides spp. with four light trap models during different seasons in the Balearic Islands. Vet Parasitol. 2013;195:150-6. 
36. Venter GJ, Labuschagne K, Hermanides KG, Boikanyo SNB, Majatladi DM, Morey L. Comparison of the efficiency of five suction light traps under field conditions in South Africa for the collection of Culicoides species. Vet Parasitol. 2009:166:299-307.

37. Probst C, Gethmann JM, Kampen H, Werner D, Conraths FJ. A comparison of four light traps for collecting Culicoides biting midges. Parasitol Res. 2015; 114:4717-24.

38. Goffredo M, Entomological MR. Surveillance of bluetongue in Italy: methods of capture, catch analysis and identification of Culicoides biting midges. Vet Ital. 2004;40:260-5.

39. Baldet T, Delécolle JC, Cêtre-Sossah C, Mathieu B, Meiswinkel R, Gerbier G. Indoor activity of Culicoides associated with livestock in the bluetongue virus (BTV) affected region of northern France during autumn 2006. Prev Vet Med. 2008:87:84-97

40. Mathieu B, Perrin A, Baldet T, Delécolle J-C, Albina E, Cêtre-Sossah C. Molecular identification of western European species of obsoletus complex (Diptera: Ceratopogonidae) by an internal transcribed spacer-1 rDNA multiplex polymerase chain reaction assay. J Med Entomol. 2007;44:1019-25.

41. Kluiters G, Pagès N, Carpenter S, Gardès L, Guis H, Baylis M, et al. Morphometric discrimination of two sympatric sibling species in the Palaearctic region, Culicoides obsoletus Meigen and C. scoticus Downes \& Kettle (Diptera: Ceratopogonidae), vectors of bluetongue and Schmallenberg viruses. Parasit Vectors. 2016;9:262.

42. Schwenkenbecher JM, Mordue AJ, Piertney SB. Phylogenetic analysis indicates that Culicoides dewulfi should not be considered part of the Culicoides obsoletus complex. Bull Entomol Res. 2009;99:371-5.

43. Beek EG. Spatial interpolation of daily meteorological data. Theoretical evaluation of available techniques. 1991. http://edepot.wur.nl/360405. Accessed 17 Feb 2018.

44. Hill MA. The life-cycle and habits of Culicoides impunctatus Goetghebuer and Culicoides obsoletus Meigen, together with some observations on the life-cycle of Culicoides odibilis Austen, Culicoides pallidicornis Kieffer, Culicoides cubitalis Edwards and Culicoides chiopterus Meigen. Ann Trop Med Parasitol. 1947:41:55-115.

45. Purse B, Brown HE, Harrup L, Mertens PPC, Invasion RDJ. Of bluetongue and other orbivirus infections into Europe: the role of biological and climatic processes. Rev Sci Tech. 2008;27:427-42.

46. EFSA Panel on Animal Health and Welfare. Bluetongue: control, surveillance and safe movement of animals. EFSA J. 2017;15

47. Brugger K, Rubel F. Characterizing the species composition of European Culicoides vectors by means of the Köppen-Geiger climate classification. Parasit Vectors. 2013;6:333.

48. Hörbrand T, Geier M. Monitoring of Culicoides at nine locations in southern Germany (2007-2008). Parasitol Res. 2009;105:387-92.

49. Kiel E, Liebisch $\mathrm{G}$, Focke R, Liebisch A. Monitoring of Culicoides at 20 locations in northwest Germany. Parasitol Res. 2009;105:351-7.

50. Larska M, Grochowska M, Lechowski L, Żmudziński JF. Abundance and species composition of Culicoides spp. biting midges near cattle and horse in south-eastern Poland. Acta Parasitol. 2017;62:739-47.

51. Versteirt V, Balenghien T, Tack W, Wint WA. First estimation of Culicoides imicola and Culicoides obsoletus/ Culicoides scoticus seasonality and abundance in Europe. EFSA Support Publ. 2017;14

52. Meiswinkel R, Elbers ARW. The dying of the light: crepuscular activity in Culicoides and impact on light trap efficacy at temperate latitudes. Med Vet Entomol. 2016:30:53-63.

53. Blomberg O, Itämies J, Kuusela K, Itamies J. Insect catches in a blended and a black light-trap in northern Finland. Oikos. 1976;27:57.

54. Carpenter S, Wilson A, Barber J, Veronesi E, Mellor P, Venter G, et al. Temperature dependence of the extrinsic incubation period of orbiviruses in Culicoides biting midges. PLoS One. 2011;6:e27987.

55. Harrup LE, Bellis GA, Balenghien T, Garros C. Culicoides Latreille (Diptera: Ceratopogonidae) taxonomy: current challenges and future directions. Infect Genet Evol. 2015:30:249-66.

56. Purse B, Nedelchev N, Georgiev G, Veleva E, Boorman J, Denison E, et al. Spatial and temporal distribution of bluetongue and its Culicoides vectors in Bulgaria. Med Vet Entomol. 2006;20:335-44.

57. Hartemink NA, Purse BV, Meiswinkel R, Brown HE, de Koeijer A, Elbers ARW, et al. Mapping the basic reproduction number (RO) for vector-borne diseases: a case study on bluetongue virus. Epidemics. 2009;1:153-61.
58. Searle KR, Blackwell A, Falconer D, Sullivan M, Butler A, Purse BV. Identifying environmental drivers of insect phenology across space and time: Culicoides in Scotland as a case study. Bull Entomol Res. 2013;103:155-70.

59. Takken $W$, Verhulst $N$, Scholte $E$, Jacobs F, Jongema $Y$, van Lammeren R. The phenology and population dynamics of Culicoides spp. in different ecosystems in the Netherlands. Prev Vet Med. 2008;87:41-54.

60. Carpenter S, Lunt HL, Arav D, Venter GJ, Mellor PS. Oral susceptibility to bluetongue virus of Culicoides (Diptera: Ceratopogonidae) from the United Kingdom. J Med Entomol. 2006;43:73-8.

61. Balenghien $T$, Pagès $N$, Goffredo $M$, Carpenter $S$, Augot $D$, Jacquier $E$, et al. The emergence of Schmallenberg virus across Culicoides communities and ecosystems in Europe. Prev Vet Med. 2014;116:360-9.

62. Ségard A, Gardès L, Jacquier E, Grillet C, Mathieu B, Rakotoarivony I, et al. Schmallenberg virus in Culicoides Latreille (Diptera: Ceratopogonidae) populations in France during 2011-2012 outbreak. Transbound Emerg Dis. 2017;65(1):e94-e103.

\section{Submit your next manuscript to BioMed Central and we will help you at every step:}

- We accept pre-submission inquiries

- Our selector tool helps you to find the most relevant journal

- We provide round the clock customer support

- Convenient online submission

- Thorough peer review

- Inclusion in PubMed and all major indexing services

- Maximum visibility for your research

Submit your manuscript at www.biomedcentral.com/submit
) Biomed Central 